\title{
WILLINGNESS TO PAY FOR BIOGAS AS COOKING ENERGY IN THE LOCAL COMMUNITIES OF HADEJIA VALLEY, NORTHERN NIGERIA
}

\author{
$\underline{\text { Maria Loureiro }}^{\mathrm{a}, \mathrm{b}} *$ y Eva Iglesias ${ }^{\mathrm{b}, \mathrm{c}}$ \\ - \\ ${ }^{a}$ Universidad de Santiago de Compostela \\ ${ }^{b}$ Ceigram. Universidad Politecnica de Madrid. \\ ${ }^{c}$ Dep. de Economía Agraria, estadística y Gestión de empresas. Universidad Politécnica de Madrid
}

Palabras clave: Adoption, Willingness to adopt, Biogas, Bioenergy, Invasive plants, Bioeconomy

\begin{abstract}
The majority of poor households in Nigeria depend on firewood to cook with dramatic impacts. The smoke of firewood use is known as the "silent killer" causing more than 95000 annual deaths (WHO, 2012) while illegal and uncontrolled logging to meet the demand of the growing population is leading to deforestation.

There is an urgent need to look for sustainable sources of biomass and Typha Project[1] has developed a biogas technology making use of Typha biomass, an invasive plant that extends over thousands of hectares in Hadejia Valley (Northeastern Nigeria). In this context, the objective of this work is to assess adoption and estimate the willingness to pay for this novel biogas technology

A logit model has been used to analyze adoption of biogas by households considering the information gathered in the focus groups and a field survey. The most relevant factor triggering adoption is related to health issues and the experience of respiratory diseases. We also observe that among those women who are willing to change, those who spend more time cooking are more likely to change to biogas. This is consistent with the fact that biogas cooking is a clean and quick way of cooking.
\end{abstract}

\section{Introduction and objectives}

Invasive cattail (Typha spp) weed in dams, canals, rivers, and agricultural lands of Hadejia Valley irrigation schemes in Northern Nigeria has become an environmental challenge with important social and economic implications for local communities that depend on farming for their living.

As of today, communal efforts and government actions to eradicate this invasive plant are costly and have had little impact. To deal with this problem (the Ministry of Water Resources of Nigeria and the World Bank launched in 2017) the Typha project which seeks to convert this threat into economic opportunities to improve the livelihoods of local communities. Specifically, one of the project goals is to develop and implement a novel technology to use Typha as feedstock for the production of biogas based on a model of rumen selected microorganisms. Hence, this is a multifaceted research with important environmental and socio-economic impacts occurring both at local and global scales.

Expanding availability of sustainable feedstock and clean energy sources for cooking is a priority to meet the goals of Agenda SDO 13 The energy progress report (IEA, 2020) finds that the global population without access to clean cooking solutions remained largely unchanged since 2010, standing at close to 3 billion. Furthermore, the rate of increase in access to clean cooking has even decelerated since 2012, falling behind population growth in some countries. Increased efforts are needed to improve access to clean and safe cooking fuels and technologies for 3 billion people

According to the Energy Access Outlook 2017, 38\% of the world's population lack access to clean cooking and typically use firewood traditional stoves or open fires in poorly ventilated spaces. In 25 countries, mostly in sub-Saharan Africa, more than $90 \%$ of households rely on wood, charcoal, and waste for cooking. Specifically, 94\% of population in Nigeria does not have access to clean energy. This situation is particularly acute and poses an enormous threat to poor and vulnerable populations in Northern Nigeria.

Traditional firewood cooking is related to severe health risks, causes deforestation, exacerbates climate change, and is unnecessarily expensive to some of the world's poorest people. According to the Nigerian Alliance of clean Cookstoves, nearly 90 million Nigerians use traditional firewood cooking stoves which is causing severe health impacts, deforestation, and climate change. In addition, as resource scarcity increases so does the cost of firewood resources, threatening affordability and living conditions of people in communities with high or extreme poverty levels.

Sadly, Nigeria experiences the highest number of smoke-related deaths in Africa. This silent killer causes 95,300 deaths annually in Nigeria where cooking smoke is reported as third cause of dead, after Malaria and HIV/AIDS. Cooking smoke causes severe health problems which particularly affects women and 
children. In addition, children born to women who were exposed during pregnancy are at risk to low birth weight, impaired mental abilities, and birth defects.

The use of wood for cooking is a major cause of deforestation in Nigeria, which is happening at an alarming rate. Carbon dioxide emissions from millions of cooking fires are contributing to greenhouse gases. Desertification, caused in part by deforestation, is contributing to poverty by forcing groups from ancestral lands to move in search of fertile pastures and has resulted in violent ethnic disputes.

Mass land clearings and logging in Nigeria - both legal and illegal - have contributed to the significant deforestation of rainforests and woodlands across the country and the African continent as a whole. And yet, wood logging remains one of the most important tools for providing fuel and power to over 120 million Nigerians who rely on its practice for firewood and cooking . According to U.N. data, Nigeria experiences and alarming deforestation rate and has lost over 2 million hectares of forest annually between 2005-2010 due to agricultural expansion, logging, and infrastructure development.

This dramatic picture reveals that the success of this novel biogas technology based on Typha biomass can help to convert a serious threat posed by Typha invasion into an opportunity to improve the livelihood of people in local communities.

This is a truly innovative technological approach, with very little knowledge or experience on biogas technology in the area of study. The engagement of stakeholders and potential beneficiaries at early stages of the project is considered a critical issue to successful adaptation and adoption.

Participation and engagement of potential beneficiaries and of other stakeholders has a pivot role from the initial stage of the project and is considered key to project success. This implementation approach is based on action research, also known as participatory research or collaborative inquiry, which motivates people to more willingly apply what they learn when they do it themselves. It aims to turn local community members into co-researchers to give input and to help solve perceived and specific problems that are affecting them every day. To this end, a participatory approach was conducted through focus group discussions with potential direct beneficiaries of biogas. The project was presented to stakeholders and followed by a dynamic participatory discussion session. Five simultaneous guided focus group discussions identified barriers, constraints, and opportunities for successful project development. Particular emphasis was given to participation of women.

A total of 54 women and men participated as potential beneficiaries to assess the novel use of Typha as feedstock for biogas. Due to cultural reasons women and men were split in different groups. Face-to-face focus group discussions were oriented around a semi-structured survey to assess potential demand for the novel use of Typha for biogas and to define strategies and incentives to promote adoption. Our findings reveal that focus group discussion is a useful tool to engage potential beneficiaries in the early stages of a project, and also ensures that local constraints and bottom-up ideas are considered in product development and technology adaptation phases of the project.

The objective of this work is to analyze the characteristics and perceptions of potential beneficiaries, to identify factors that determine adoption and to assess their willingness to pay for this new biogas technology.

Results allow to understand and identify constraints and opportunities to guide project development and identify strategies to foster adoption.

\section{Methodology}

A field survey survey was conducted in seven communities/sectors: Akubushin, Auyo, Auyakayi, Furawa, Gatafa, Marina, and Yamidi. All the communities belong to Auyo Local Government Area (LGA) of Jigawa State. The state which is located in the Northern part of the country, covers a land area of about 22,210km2 or about 2.2 million hectares and lies between latitudes 100 57' North and 130 03' North and longitudes 80 $08^{\prime}$ 'East and 100 37' East.

The communities were purposively selected based on their participation and abundance of Typha grass in the area. A total of 365 respondents were randomly selected from the list of about 2,000 farmers obtained from water users association in their respective communities/sectors for the survey. The data collection was made using a face to face questionnaire. The surveys were applied in two periods. The first was in the months of June- July 2019 and May 2020 new questionnaires were applied. The survey was conducted at the household level. To address gender issues, two different questionnaires were applied, the Household Head and the Wife Questionnaire. 
Questionnaire design is based on previous focus group discussions conducted during the project inception workshop. The questionnaire is made up of five sections: Personal and family data, Typha invasion and impact, decision making and collective action, Energy sources, and Adoption of biogas technology based on Typha. Both questionnaires share the same structure, but specific questions that directly concern women have been added. Women and men questionnaires were conducted separately due to cultural traditions and to encourage women to express their views.

Based on field survey results we model adoption or willingness to adopt and willingness to pay for Typha based biogas. A logit model has been used to analyze adoption of biogas by households. Given the common use of this binary probabilistic log-likelihood, we omit its description.

Willingness to pay (WTP) analysis has been conducted considering the data structure (payment card fomat) used in the survey. Cameron and Tivedi (2010, 548-550) discuss the differences among censored, truncated, and interval data. If the willingness to pay for the jth individual is somewhere in the interval $\left[y_{1 j}, y_{2 j}\right]$, then the likelihood contribution from this individual is simply $\operatorname{Pr}\left(y_{1 j} \leq Y_{j} \leq y_{2 j}\right)$. For censored data, their likelihoods contain terms of the form $\operatorname{Pr}\left(Y_{j} \leq y_{j}\right)$ for left-censored data and $\operatorname{Pr}\left(Y_{j} \geq y_{j}\right)$ for rightcensored data, where $y_{j}$ is the observed censoring value and $Y_{j}$ denotes the random variable representing the dependent variable in the model. Estimation has been conducted using the STATA software, with the

Let $y=X \beta+\epsilon$ be the WTP model where $y$ represents the latent WTP vatiable ; X is a vector of explanatory variables and $\epsilon \sim N\left(0, \sigma^{2} I\right)$.

For observations $j \in C$, we observe $y_{j}$, that is, point data. Observations $j \in L$ are left-censored; we know only that the unobserved $y_{j}$ is less than or equal to $y L_{j}$, a censoring value that we do know. Similarly, observations $j \in R$ are right-censored; we know only that the unobserved $y_{j}$ is greater than or equal to $y_{R j}$. Observations $j \in I$ are intervals; we know only that the unobserved $y_{j}$ is in the interval $\left[y_{1 j}, y_{2 j}\right]$.

The log likelihood is

$$
\begin{aligned}
\ln L= & -\frac{1}{2} \sum_{j \in C} w_{j}\left\{\left(\frac{y_{j}-x \beta}{\sigma}\right)^{2}+\log \log 2 \pi \sigma^{2}\right\} \\
& +\sum_{j \in L} w_{j} \log \log \Phi\left(\frac{y_{L j}-x \beta}{\sigma}\right) \\
& +\sum_{j \in I} w_{j} \log \log \left\{\Phi\left(\frac{y_{R j-x \beta}}{\sigma}\right)\right\} \\
+\sum_{j \in I} & w_{j} \log \log \left\{\Phi\left(\frac{y_{2 j}-x \beta}{\sigma}\right)-\Phi\left(\frac{y_{1 j} x \beta}{\sigma}\right)\right\}
\end{aligned}
$$

where $\Phi()$ is the standard cumulative normal and $w_{j}$ is the weight for the jth observation. If no weights are specified, $w_{j}=1$. If aweights are specified, $w_{j}=1$, and $\sigma$ is replaced by $\sigma / \sqrt{a_{j}}$ in the above, where $a_{j}$ are the aweights normalized to sum to $\mathrm{N}$.

\section{Results}

Based on the information obtained through surveys conducted in 7 communities in the Hadejia Valley, we identified that households do not have the economic possibility of installing a biodigester themselves. Despite this, we identified that there is a high willingness to adopt the technology $(76 \%)$ and that the communities are very united which would allow the installation of community biodigesters that would lead to savings in effort and money. These results are consistent with the literature reviewed where the variables 
that influence the adoption of clean cooking technologies are household income, livestock, and access to credit

Table 22 Descriptive Statistics employed in Regression Analysis

$\begin{array}{llllll}\text { Variable } & \text { Obs } & \text { Mean } & \text { Std.Dev Min } & \text { Max } \\ & & & & & \\ \text { Biogas Cooking } & 365 & 0.1 & .3 & 0 & 1 \\ \text { Female } & 365 & 0.6 & .5 & 0 & 1 \\ \text { Age } & 365 & 44 & 10 & 18 & 68 \\ \text { HH Size } & 365 & 11 & 5.4 & 0 & 33 \\ \text { Electricity Access } & 365 & 0.25 & 0.44 & 0 & 1 \\ \text { Respiratory Disease } & 365 & 2.12 & 1.05 & 1 & 4 \\ \text { HH Monthly Income } & 365 & 2.11 & 1.00 & 1 & 4 \\ \text { Time Spent Cooking } & 365 & 6.29 & 4.08 & 1 & 15 \\ \text { Years Formal Education } & 207 & 9.54 & 4.77 & 0 & 20 \\ \text { Firewood collector } & 365 & 0.3 & 0.46 & 0 & 1 \\ \text { Power important decision } & 365 & 3.9 & 1.01 & 1 & 5 \\ \text { Source Information (radio) } & 365 & 0.73 & 0.45 & 0 & 1\end{array}$

Note: $\mathrm{HH}=$ household

A logit model has been used to analyze adoption of biogas by households. The willingness to adopt biogas for cooking has been modeled considering the information gathered in field surveys. In particular, whether the respondent was a female, whether someone in the household suffered from respiratory diseases and the opportunity cost of other energy alternatives (such as wood), as well as other related social norms, such as whether the respondent felt it had the power to make important decisions, whether had access to important information sources, and other variables including education (proxy) and household income had been included.

As it turns out, among the considered socio-economic and cultural variables, the most relevant factor triggering adoption is related to health issues and the experience of respiratory diseases by children, carrying a positive and statistically significant coefficient. Other variables, showing that the respondent is a female and has power to make important decisions carry negative effects.

A potential interpretation of these results is that female respondents may not have the actual power to change their kitchen appliances anyway, and those who have the power may not have the resources as they are widowed or living alone. The same results seem to suggest that respondents who spent more time cooking are less likely also to change to biogas. The reasons can be multiple, including both, economic and cultural; as this energy source may require substantial changes in the manner of preparing traditional meals and staple foods. However, we also observe that among those women who are willing to change, the coefficient is positive which means that spending more time cooking is associated to a higher willingness to pay for biogas use. This is consistent with the fact that biogas cooking is a clean and quick way of cooking which is, together with health improvement, one of the main advantages perceived by beneficiaries (Loureiro et al 2018; IRENA 2017)

4. Conclusions

A survey has been conducted face-to-face in 150 households in Hadejia Valley in order to assess concerns and potential uptake of biogas adoption generated from Thypha biomass. Our results show the important potential of biogas as a new energy source for households in Hadeja Valley. In particular, mean WTP per household is about 309 Nigerian Naira per day/household $(0.81 \$)$. WTP is also higher for larger households, those who suffered from respiratory diseases and those cooking longer per day.

The cultural context makes evident the differences between men and women in terms of opportunities and resources. Men and women have access to different sources of information, the most privileged being men. This leads to women being left behind in the process of adopting biogas. Policies promoting women empowerment are essential, its been demonstrated that when women are given a voice results and development tend to be better.

According to the information obtained from the survey we can see that they are cohesive communities, which offers other organizational opportunities that can be used to transmit new knowledge and participate 
in community work. In this sense, it is important to promote and support women's organizations to facilitate their integration, from informative meetings to training and evaluation processes.

Another aspect to highlight is that respondents state that the Typha invasion has negative impacts.

Cleaning of the Typha is necessary, even a couple of times a year to avoid the damage into the water

channels. This is encouraging for the development of the Project since obtaining the raw material for biogas does not generate an extra workload, but it would generate health and economic benefits for the households

We conclude that improving energy access in a sustainable and affordable manner may profoundly impact local communities on multiple aspects of human development, from poverty to gender equality, health, environment and climate change.

increase bioenergy availability with improved food security while ensuring positive social and environmental impacts in rural Africa.

\section{References}

International Energy Agency; International Renewable Energy Agency; United Nations Statistics Division; World Bank; World Health Organization. 2020. Tracking SDG 7 : The Energy Progress Report 2020. World Bank, Washington, DC. (C) World Bank.

https://openknowledge.worldbank.org/handle/10986/33822 License: CC BY-NC 3.0 IGO. 